** NB. This document is the accepted manuscript for Journal of Contemporary Painting, prior to proofing and copyediting, and without illustrations **

\title{
On Situating Painting: An Interview with Karin Kneffel
}

Sunil Manghani

\begin{abstract}
Karin Kneffel came to prominence in the 1990s, known for her finely rendered portraits of animals, interiors, and still life paintings. Her handling of light, shadow and the complex interplay of reflective surfaces leads to challenging illusionist spaces. Through striking juxtapositions, foreshortening, and exaggerated scales, Kneffel transforms otherwise overlooked objects. In this interview, the artist offers critical reflections on her practice. The interview is divided into three strands: (1) Situated Painting, begins with specific considerations about the political conditions within which one 'works' as an artist; (2) Situations of Painting, turns attention to painting as medium and form; and (3) Situating Painting, examines both practical and aesthetic considerations of displaying work, and in particular an exhibition at the Mies van der Rohe Pavilion in Barcelona.
\end{abstract}

Keywords: Commitment, Illusionist spaces, Karin Kneffel, Mies van der Rohe Pavilion, Painting 
Karin Kneffel came to prominence in the 1990s, known for her finely rendered portraits of animals, interiors, and still life paintings. Her handling of light, shadow and the complex interplay of reflective surfaces leads to challenging illusionist spaces. Through striking juxtapositions, foreshortening, and exaggerated scales, Kneffel transforms otherwise overlooked objects. Two recent projects, Haus am Stadtrand [House at the Edge of Town] at the Museum Haus Esters in 2009/10, and then La ventana y el espejo [Window and Mirror] at the Mies van der Rohe Pavilion, in Barcelona in 2014, led to the production of a significant new body of work presenting very specific demands on the viewer through careful site-specific installation. In dialogue with Sunil Manghani, Karin Kneffel offers critical reflections on her practice. The interview is divided into three strands: (1) Situated Painting, begins with specific considerations about the political conditions within which one 'works' as an artist. Reference is made to Sartre's notion of 'commitment', suggestive of underlying critical (political) questions of the self, of reality, and of mediation; (2) Situations of Painting, turns attention to painting as medium and form, staking out a position for painting vis-à-vis other forms of representation and mediation; and (3) Situating Painting, examines both practical and aesthetic considerations of displaying work, and in particular Karin Kneffel's exhibition at the Mies van der Rohe Pavilion. Whether 'situated', 'situations of' or 'situating' painting, each of these themes inevitably interleave. 


\section{Situated Painting}

Manghani: This interview is to be placed within a special issue of the Journal of Contemporary Painting on 'Commitment and Painting'. Its starting point was a symposium for which I gave a talk referencing Jean-Paul Sartre's notion of the committed artist. Given the significance of the early post-war period, it is perhaps inevitable Sartre wished to stake out an overtly political role. The writer, he remarks, is 'a mediator and his commitment is to mediation'. This might sound like the writer is simply a communicator, concerned as much with the medium as the message. Yet, as we know, his existentialist account presents a more challenging consideration. Revisiting Sartre's remarks on writing and painting, I sought a reappraisal of the anti-aesthetic and postmodern debates of the 1980 s; ultimately to re-situate painting as commitment in itself. For me, what emerged was the suggestion that rather than try simply to place painting within wider social networks, we need to remind ourselves of painting's inherent appeal to freedom (as is the case for other art forms, though each within their own specificities). As Sartre puts it, the artwork 'does not serve my freedom, it requires it'. To explain this further, he writes: 'the appearance of the work of art is a new event which cannot be explained by anterior data. And since this directed creation is an absolute beginning, it is therefore brought about by the freedom of the reader, and by what is purest in that freedom. Thus, the writer [and painter] appeals to the reader's freedom to collaborate in the production of his work'. Keeping in mind the so-called committed artist, I wonder if I can begin with a direct, political question about the status of your work and yourself as an artist. Martin Hentschels' (2014) article, 'The Suggestive Power 
of Karin Kneffel's Art', begins as you know with the quote from Gerhard Roth: 'We are constantly engaged in constructing realities'. In looking at your work - the use of layers, the deep enquiry into time and personal and cultural memory-all is suggestive of underlying critical questions of the self, of reality, and of mediation. How would you describe yourself as 'committed' in any specific way as an artist living and working in a particular historical moment?

Kneffel: 'Conversations with the pilot are forbidden' Picasso once told an interviewer and I feel a little that way, when I navigate my way through your complex question. We always include politics when we use the word commitment, and why shouldn't we. When I paint, I always paint with what already exists against what already exists. I move existing perspectives; I change the disposition of objects, which might only have had one function before and give them a new purpose; I change the light and with that light I illuminate this constellation differently. What story do I illuminate differently with that light? That's what I ask myself. I have my experiences, including culture, history, life and everything that comes my way: we all know that what is supposedly higher culture is made of the same material as that which is lower; and it is not just idle talk that you, as an artist, often can't judge exactly where you stand at the moment. The fact that I relate to my contemporary situation is important to me as it forms my style, but I can't remain always in the contemporary moment as a painter. There is of course the whole history of art in which I have to position myself. I believe we are going to talk about all the things that I deal with in the course of this conversation, but the tension in which I live is very personal and universally applicable at the same time. I teach at an academy and have a 
responsibility for the students and the academy, which I also and especially have for my art: my form of engagement is made up of all these different spheres.

Manghani: Yes, of course, positioning ourselves politically means always to position ourselves in relation to others and 'other' situations and points of view. There is a further reference to Sartre I'd like to make. The idea of the artwork as having an inherent appeal to freedom relates to Sartre's understanding of artistic creation as a form of 'bringing the world into being'. He suggests of the artwork that we are not only its director, but its producer. Yet, crucially, as the creator of the artwork we get to see only that which 'sinks back into its dark permanence', since the artist cannot look at their own work as a worki.e. as a finished piece. His suggestion is that the painter can never know when the painting is finished; it can only ever be for someone else to look at. It is always committed to another: 'There is no art except for and by others'. Are you sympathetic to this characterization of the artwork and artist's relationship to it? In one sense, this is a question about how you feel you relate to your work while in the studio and what it becomes and how you relate to it once it leaves that environment.

Kneffel: I know when a painting is finished. I also find it strange to assume that a painter can't understand this involvement and obvious requirement. I know my pictures so well, as no one else will ever know them, because I've created them physically in a lengthy process, and added my soul, if you like. So naturally, I do enjoy knowing about some details that will hardly be perceived by anyone else. This doesn't mean that I don't appreciate the beholder's perspective and observations. Quite the opposite. But I have to 
put this into the background as far as I'm concerned to cope with this complex interplay of producing pictures in my studio for other spaces: what happens with naturally autonomous pictures, which are used just as naturally in other spaces now and that are changed as a result? The question is 'how'? I have my own way of experiencing it and take it into account in two ways: on the one hand I hang the pictures for my exhibitions myself. This is how I have done it until now. After painting them, the pictures take on another form during this process, for me too. I sort of transform my pictures and their appearance into objects. I then like to spend time in the exhibitions to experience how that works. To see what it does to the visitors in the way they speak and think.

<INSERT FIGURE 1><Caption> Figure 1: Karin Kneffel, Untitled, 2009/03, Oil on canvas, $180 \times 550 \mathrm{~cm}$.

<INSERT FIGURE 2> <Caption> Figure 2: Karin Kneffel working in the studio on the painting: Untitled, 2014/03, $180 \times 300 \mathrm{~cm}$.

Manghani: In preface to Martin Hentschel's essay on your work, 'The Painting as an Amalgam' (2009), there are four photographs of you working on a very large format work (Figure 1) for the exhibition Haus am Stadtrand [House on the Edge of Town], $2009 / 10$. I want to come back to this project in more detail later on, but there is 
something very striking to me in these photographs about painting as a form of labour (Figure 2). The canvas is all blocked out, presumably in charcoal, which in itself must have been a painstaking job. A key portion of the canvas is a scene through a window, which you have already painted. Despite the closeness of the camera lens, the dappled reflections of trees and interior of the room through the glass all appear to be genuinely before you as you work with your brush on other areas. Visually, then, there is a beguiling oscillation between the illusion of the real and the 'reality' of the painting in draft form. These photographs make for an interesting statement on the painter as a labourer of illusion. A large portion of the canvas is all brickwork, which plays a deliberately mundane role both visually and substantively in relation to the rest of the composition. Overall the painting presents a confusing sense of interior and exterior spaces. We are apparently looking through a window across to another window, which shows us an interior of a room. The reflected image of a lamp, a ghostly chair, a disembodied screen, the branches of a tree, a plant, and a large expanse of a pleated curtain are all in our foreground, as if in the space from which we are viewing the painting. We can return to the specifics of your composition and aesthetic, but equally I'm struck by the toil undertaken. Like a builder (similarly dressed in overalls) you have to paint each and every one of the bricks, rendering them life-like in each instance. The commitment to paint is here very simply a commitment to work. It is a form of employment: to put in the hours; to physically work at making the 'reality' of the picture become apparent. I'm struck then, between the time of the painting (in this case a real place and space, combined with a dreamlike temporality) and the time it takes to paint. 
Of course, as an illusionistic practice, the former 'paints over' the reality of the latter. I'm wondering, how do you experience time in the studio: is it a form of labour?

Kneffel: 'Work'. 'Producing'. Naturally I'll go to the studio and work. This is a process that captivates me for a long time and I do enjoy it. Time takes on a different meaning when I paint. It is no longer controlled by the clock, as the problems and questions to do with painting create a very unique form of time. It is rather difficult at times to coordinate it with the daily routine. Those things in the pictures that have fallen out of the world, that feeling of being a part of the process, straightening up the body and back, the usual chores. I don't necessarily consider an economy of work: I use as much time as is necessary or seems necessary to me to paint a wall or a curtain. When I'm done there is a certain post-production tremor emanating from the already resting hand, causing a crack in each wall, constantly trying to split every single thing into two. Inherent in the seemingly perfect surface of the wall is of course also doubt, the question of the reality of what I'm painting and of its image. And my soliloquy - and thus the processes of creating the picture - leads to talks about what I've done. I do understand what you mean when you talk about the ghostlike chair, the disembodied screen, and the other things. That's this tremor emanating from the things in the pictures. That's the thinking I try to express in my paintings: the relationship between reality and what is real, which I take in and direct towards the picture.

\section{Situations of Painting}


Manghani: I'm keen to ask the more direct question: Why in particular did you choose to paint? Why this medium and not others? The question is pertinent to the period in which you were first emerging as an artist. Having studied German and philosophy in the late 1970s, you went on to study as a painter at the Staatliche Kunstakademie, between 1981-1987. At this time photography and multi-media were prominent within European and American art practices, yet you chose to work with canvas, brush, and paint, and have done so ever since. Were you deliberately reacting against the claims of the "end of painting', or did the debates at the time simply not have any real purchase for you?

Kneffel: Dusseldorf was an Academy that had everything. All the professors and students were there that at least the art market considers important today. This may sound exaggerated but that's what it was when you look back. Uecker, Beuys, Richter, Graubner, Lüpertz and the Bechers, I can list who I want. Then there are those who did not belong to this circle as an artist but, naturally, were and are artists to us nevertheless and embodied that at the Academy. And a relatively great number of students studied almost simultaneously there that later became successful artists. Somehow you could feel it, if I may say so. This created self-confidence but there were also suppression, fights, nasty stuff, of course. When I left school I wasn't as young as you apparently have to be today, so I already knew what I wanted and pushed it through. To me, painting was selfevident and never in question. That's what I wanted to do. At the Academy, however, I had to learn that it meant that I naturally - unfortunately 'naturally' - had to make my way in what was a male domain in a certain way. These years were actively discriminatory in 
terms of the gender issue, and in retrospect I sometimes wonder about the unconscious toughness I had to make it through. But that's what made it interesting. When I painted elaborate animal portraits, few people understood what I was doing but I did so with a history of art behind me, which I thought remained relevant. Looking back there was nevertheless a kind of solidarity among the students that persisted, at least individually, even after we left the Academy.

Manghani: Given this history then, and the social and creative environ of the Academy, it is perhaps inevitable that there are all sorts of evocations in your work about painting vis-à-vis other forms of representation. And if we turn more directly to the paintings, they can be situated in very specific ways to photography, film, mirrors, water, architecture, patterns and glass. Related to which of course would be questions of scale, porosity, and points of view. In thinking, then, about situations of painting, or more particularly situations of paint (to refer to the materiality of the medium), I'd be interested to hear how you approach painting - the steps you take and processes involved. This is a more practical question, and no doubt, over time, you'll have felt there are different phases and shifts in your working practices. How would you reflect on these?

Kneffel: This is really a beautiful question, because it also concerns me very much. I stopped using colour paint as mere material, conceiving colour as thick or impasto for example, although I did use it in such a way in the past at times. Yet I like to play with the effects of painting, and also the illusionistic appearance of impasto, the texture of the colour and so on, but it only has a marginal materiality. That gives me pleasure, 
especially because I don't use colour, the oil paint, in a naive way. For example, I painted that Macke picture because it hung in the 'Haus Lange' (see Figure 3). I gave it a painterly structure and colour palette that was, despite its similarity to the Macke, of course completely different from the one in the original. If you look at my paintings, you'll see that a different reality is attributed to the paintings of Macke, Chagall etc.: they are there, without mirroring effects, without reflections on them. This lends them a luminosity almost reminiscent of a display. I wanted to paint the Chagall painting that is now in the museum in Eindhoven with the same colours that Chagall has used. This is a very sensitive form of similarity and not a desire to copy something. My view of paintings and sculptures has changed by investigating them in my pictures: today I think differently and more sympathetically about Lehmbruck than I did before painting his sculptures. The art in the interiors painted by me is therefore more physical as it is more colourful and clearer than many other items in my pictures. I can also look at it like a form of display or a composite that - just as someone might click through images - shows a series of pictures one after the other, or even simultaneously.

<INSERT FIGURE 3><Caption> Figure 3: Karin Kneffel, Untitled, 2014/02, Oil on canvas, $180 \times 270 \mathrm{~cm}$.

<INSERT FIGURE 4> <Caption> Figure 4: Karin Kneffel, Untitled, 1998, Oil on canvas, 300 x $200 \mathrm{~cm}$. Displayed at the MAC, Museo de Arte Contemporáneo, La Coruña. 
Manghani: Let's turn to the 'object' in your work. Your paintings are well known for how they transform the everyday. Indeed, your veristic rendering of wallpapers, furniture, curtains, animals, fruit, and even fire, all seem to offer a 'way of seeing' that goes beyond the objects themselves. Your large work depicting fire, for example, which spans seven meters (across four panels) is an incredible capturing of the ephemerality of a blazing fire. Yet, perhaps because of the scale and flattening of the perceptual space (it is not the same as a photograph of fire), the painting is more an analysis than the spectacle of fire. Similarly, your various paintings of grapes offer a realism that goes beyond our usual perception of reality (see Figure 4). There is of course the Greek myth of Zeuxis presenting to Parrhasius a painting of grapes that appeared so real and succulent that birds flew down to peck at them. However, in your case, I'm not sure if the birds would quite know what to do. There is something too real about your grapes. I'm inclined to think of Neue Sachlichkeit (New Objectivity) and of the verists, who 'tear the objective form of the world of contemporary facts and represent current experience in its tempo and fevered temperature' (Kaes et al. 1994: 492). Similarly, I'd suggest you distort nothing, yet provide an entirely new orientation. What comes to mind is an early essay by Roland Barthes (2000 [1953]) on seventeenth century Dutch painting. Barthes begins the essay with reference to Saenredam, who he describes as 'a painter of the absurd [...] To paint so lovingly these meaningless surfaces, and to paint nothing else - that is already a "modern" aesthetic of silence' (Barthes, 2000: 62). By the end of the essay we learn that 
the aesthetic is of the gaze itself. Barthes ends with the enigmatic line: 'Depth is born only at the moment that spectacle itself slowly turns its shadow toward man and begins to look at him' (73). From the painstaking attention you give to objects and surfaces in your own paintings, as well as a keen awareness of historical genres of painting, I wonder to what extent you might feel some affinity with this suggestion of a spectacle's own shadow turning itself out to look at the viewer?

Kneffel: This change of subject you speak about is a famous motif and leads to a kind of magic material self-life of things, which is the only way to explain Barthes. That interests me but it doesn't apply to me. 'Meaningless Surfaces, Lovingly Painted', 'Aesthetics of Silence' is something I can very much relate to. But first things first: naturally, my pictures are constructed and I do not even wish to be moved by things during the painting process. This happens before I paint, when I work out everything as accurately as possible and try to picture as best as I can what is going to happen on the canvas. It is natural that this can be planned only to a certain limit and that things change during painting. But I'm aiming at something else: the degree of complexity, reflections, spaces, relations of things and people to each other are increasing in my pictures and demand my full attention, so that the effect you talk about comes about: the not quite uncontrollable interactions, which - simplistically expressed - emanate from the paintings themselves and onto the viewer. They are not that easy to read, some relationships in the paintings might be or are intended to be unrecognizable, which is why I like the effects of meaningless surfaces, even though you meant something else. Maybe then happens what 
might sound surprising at first but is real: that the inner monologue, this permanent talking, is actually stopped by viewing a painting and one is embraced by a picture.

Manghani: Keeping this complexity in mind, then, I'd like to turn to the many surfaces and filters that are at play. Perhaps this is something that has become more apparent in your recent work with your exhibition Haus am Stadtrand at the Museum Haus Esters in 2009/10, and then La ventana y el espejo at the Mies van der Rohe Pavilion, in Barcelona in 2014. I want to come onto the practicalities of these exhibitions - in terms of how you situate the works within the specific architectural environments and histories of these exhibition spaces - but before doing so, as a way of rounding off the theme of situations of paint/ing, I'd like to think a bit more about the imagery you work with, and its framing. From 2004, you have a series of panoramic works of a tightly cropped bedroom scene, with the focal point being a television set. In the foreground we see the corner of plush bedding, then centre-point is a television screen (with what look to me like Bmovie type imagery), behind which are curtains or a desk, and then to the right of the frame (set on a diagonal) a slightly disorientating set of surfaces and amalgam of objects (including in one a bearskin rug). You also have some works from 2013 with explicit references to Hitchcock films. As with the large format work mentioned earlier from the exhibition Haus am Stadtrand, you again work with an imagined interior space of the viewer that is reflected back against the window through which it is possible to see 'outside'. In the case of these Hitchcock paintings we see a shot of a film on a screen reflected against a windowpane, which evokes a dreamlike quality where again it is difficult to distinguish between interiors and exteriors. Another complex framing device, 
which you turn to extensively for Haus am Stadtrand, is the use on the 'top' of the painting of the appearance of water droplets and writing on condensation. I'm curious as to how you orchestrate all the different elements within a single painting. In part, I think my curiosity is about where the image truly resides, and when it takes effect. Victor Burgin (2004: 7-28) has written of 'sequence-images', which are neither strictly 'image' nor 'image sequence', but an element of remembered film of such brevity they might almost be stills. He describes how 'a concatenation of images raises itself, as if in bas relief, above the instantly fading, then forgotten, desultory thoughts and impressions passing through my mind as the train passes through the countryside' (21). These 'sequence-images' are the starting point of Burgin's digital projections, yet he produces works of a very exacting nature, made with measured construction. Your paintings are similarly the result of very careful planning and fabrication, but is this then a construction of imagery which otherwise resides elsewhere? In other words, is your imagery something that emerges in a much more intuitive and even unconscious state? If so, how do you then transpose this to a painterly process; how do you allow the imagery to cohere as a single painting of a singular moment 'as if in bas relief'?

Kneffel: We are right in the fabric of my pictures, and perhaps you can understand that I can't provide precise information. Your description of the pictures and their context is so beautiful that it is almost enough, but I don't want to wiggle out of answering your question. Painting permits a simultaneity of things in an image that are actually different. Whether 'now' is the single moment, as you say, I will leave undecided. Introducing time and space into a picture and not being satisfied with what I find changes me and an 
image. Something becomes visible that was not there before. Something that is connected with the past and its future at the same time. The eye can wander from perspective to perspective, and the flickering light entering from somewhere else creates clarity as well as confusion about the story of the different time levels, all of which are worked into the picture. What shall I call it: multi-perspective, certainly, a nice ambiguity without randomness, that I understand as strolling through a picture. Staying in motion, discovering new relationships with an unobstructed view. That's it.

\section{Situating Painting}

Manghani: I've already mentioned the two recent exhibitions, Haus am Stadtrand (2009/10) and La ventana y el espejo (2014). Both of these share the common thread of the architect Ludwig Mies van der Rohe. Also, both these projects offered opportunities to think about your painting practice in a more expanded sense, allowing for an installation of paintings and for you to work in relation to broader questions of architecture and notions of place/space. Your practice extends to situating painting rather than merely exhibiting works. In the first case, you were invited to put on a solo exhibition in Museum Haus Esters (Krefeld, Germany), which is a building designed by Mies van der Rohe. This was the residential home of the family Esters (prior to its use as a museum) and you blend different histories together within a single image (again using the different surfaces and techniques we've already discussed). Following this, you were 
then offered a solo exhibition at the auspicious Mies van der Rohe Pavilion in Barcelona. As a major architectural statement (with its distinctive openness, blending both inside and outside), and as a site that does not permit any alterations, it is an unusual venue for an exhibition of painting. Indeed, the building is rather more an exhibition of itself. You are one of several notable artists to have been invited to make some kind of intervention. The photographer Jordi Bernadó, in 'Second Reconstruction', for example, rather dramatically removed the doors to photograph the venue as it was originally intended. While Ai Weiwei replaced the water in the pavilion's two pools with coffee and milk. What were your thoughts in approaching these two projects and how would you characterize your approach to these spaces?

Kneffel: One thought has always occupied me during the preparations: that the duration of this exhibition would be so short, only a fortnight. Nevertheless I would think, paint, discard, think some more and invent the construction for more than a year, and bang, it would appear, it would be seen or not, discussed or not, and then it would disappear from the location it was meant for. This thought has encouraged me to think the work through and execute it as accurately as I could. That two people had done it before me encouraged me to make something possible in a location which is actually impossible for paintings: the appearance of paintings. And of course it was compelling for me: I could continue to work on my Mies paintings (since the work for Museum Haus Esters) but give them a new story, the story of the pavilion; so becoming part of a bigger picture, made up of ever new constellations. 
Manghani: In the accompanying book for Haus am Stadtrand there is a floor plan of the exhibition. It shows how you were able to use the windows of the building to create viewpoints upon the paintings. The large format work we have already mentioned, which presents a layering of scenes through a window, is itself looked upon by a real window. The play of painterly and natural light must have been satisfying to work with. There is also your painting of a staircase (leading nowhere, only to a patterned wallpapered wall), which creates a slightly unnerving trompe-l'œil effect. What was the timescale for researching this project, producing the paintings and then installing the works? It would seem to represent a 'production', beyond you simply working as a painter. Would this be a fair description?

Kneffel: Locations for my pictures have always been of interest to me. It often happened that I fit them into buildings, art galleries and museums while painting. My pictures apparently change, but only apparently, based on the location. 'House in the Suburbs' was different in this respect, as many exhibitions at this location are characterised by the fact that the artists work for and interact with the building and create their own working groups. That's what interested me during preparatory work; and then of course the question: What was there before, what was visible before? That's what I have integrated into my pictures - as quotations. An almost archaeological interest became increasingly strong over the course of time: how have inhabitants lived in the Bauhaus-house on the outskirts of the city? How did it look? What was the furniture, which pictures hung there? Then you get into a maelstrom of motivational research, which leads to a small number of 
black and white photographs from that period, which illustrate at least one thing: there's a certain tension between the puristic architecture and the interior - it just doesn't fit. Or, at least, I wonder: What impression do we get from this house when we enter it, knowing that we will find photos of Gursky, paintings of Richter and whoever else? A beautiful museum space. But I wanted to show what it used to be like when people lived there. Not as a verismo. I didn't want to show what it really was like, but using the means of my painting I wanted to paint a picture of a picture of the image that we experience today.

<INSERT FIGURE 5> < Caption> Figure 5: Karin Kneffel, Untitled, 2014/04, Oil on canvas, $180 \times 300 \mathrm{~cm}$, as hung on the reverse of another painting which looks out through the glass of the Mies van der Rohe Pavilion, Barcelona, 2014.

<INSERT FIGURE 6> < Caption> Figure 6: Karin Kneffel, Untitled, 2014/03, Oil on canvas, $180 \times 300 \mathrm{~cm}$, seen through the glass from the exterior of the Mies van der Rohe Pavilion, Barcelona, 2014.

Manghani: Echoing my previous remark, and to draw things to a close, I'd like to ask something further about the exhibition at the Mies van der Rohe Pavilion. Again, this would seem to require a whole level of production beyond the paintings. You produced two new, striking canvases of the pavilion itself. Significantly, these were placed back to 
back, and, crucially, one of these paintings (already a work of complex reflections and refractions) was exhibited looking outwards through the glass of the building. To display the painting in this way brings your aesthetic to a climax, but also your work here becomes a form of public art. The critic David Joselit, in 'Painting Besides Itself' (2009), has remarked upon what it means to place paintings in 'networks' (prompted in part by the ubiquity of digital networks). I have been critical of his account (Manghani, 2016), but I wonder if perhaps your paintings seen through the glass of the pavilion get a little a closer to the idea of transitivity he raises - and specifically because the very aesthetic you are engaged in is further replicated by situating the paintings through the glass, which in turn makes the work available to a 'network' of public viewing, (no doubt to be carried away by a further replication of screens as people photograph the site through their mobile phones).

Kneffel: The Barcelona Pavilion of Mies van der Rohe is essentially the challenge of the interaction between inside and outside, between the public and the intimate. The paintings attempt an impossibility in a space that doesn't want to be there for paintings: to show the interior and exterior of a space that has been reconstructed and altered. The reconstruction significantly differs in many ways from the original Mies building. Paintings cannot be one thing in such a space: illustrative. You cannot hang them on a wall - there is simply no possibility for this - but even if it would have been permitted to create a classical museum situation, I wouldn't have wanted it. I had to structure the space with the paintings and I intentionally began with the exhibition at the entrance of the room. From there I assigned the space from anew, organized it differently. And I 
wanted that this large painting could not be seen in its totality when entering the pavilion but would still capture and touch everyone. Of course it is important to me to ask: how will it be viewed and perceived, how will the reflections be multiplied because the place adds its own reflections and those of the viewers? It produces a nice infinity in the midst of the rapidly passing time, which everybody tries to capture with selfies, but which actually shorten or puncture the experience in a very obsessive way. My paintings are there, a vibrant painting-wall amidst the crystal clear Mies structure. They talk about time without trying to be mystical: they have changed the space and will remain as paintings but also as paintings at this location. I might summarize it all without terminating it: I might not point out any new ideas, but I open new approaches to the seemingly familiar.

\section{References}

Barthes, Roland (2000) [1953] 'The World as Object', trans. by Richard Howard. A Roland Barthes Reader, ed. von Susan Sontag. London: Vintage.

Burgin, V. (2004), The Remembered Film, London: Reaktion Books.

Hentschel, Martin (2009) 'The Painting as an Amalgam', in Karin Kneffel: Haus am Stadtrand / Hour on the Edge of Town, ed. by Martin Hentschel. Museum Haus Esters, Krefeld / HatjeCantz, pp.11-18. 
Hentschel, Martin (2014) 'The Suggestive Power of Karin Kneffel's Art' in Karin Kneffel: La ventana y el espejo (catalogue). Arte Contemporáneo y Energía, A.I.E, pp.740.

Joselit, David (2009) 'Painting Beside Itself', October, No. 130, Fall 2009, pp. 125-134.

Kaes, Anton; Jay, Martin; Dimendberg, Edward, eds (1994). The Weimar Republic Sourcebook. Berkeley: University of California Press.

Manghani, Sunil (2016) 'Painting as Commitment', Journal of Contemporary Painting, Vol. 3, No. 1-2, pp. ([NB. ref to main article in same issue]

\section{Contributor Details}

Karin Kneffel was born in Marl, Germany in 1957. From 1981 to 1987 she studied at the Staatliche Kunstakademie Düsseldorf with Johannes Brus, Norbert Tadeusz and Gerhard Richter. She has been the recipient of various honors and awards, including the Karl Schmidt-Rottluff Grant (1991), the Lingener Kunstpreis (1994), and a Grant from the Villa Massimo, Rome (1996). Her work has recently been shown at Kunsthalle Tübingen (2010), Museum Haus Esters, Krefeld (2009-10), and the Mies van der Rohe Pavilion in Barcelona (2014). In January 2006 the Ulmer Museum, Germany hosted a retrospective 
of her work. From 2000 to 2008 Kneffel taught Painting at the University of the Arts in Bremen, Germany. She now lives and works in Düsseldorf and Munich and has held a professorship in painting at the Academy of Fine Arts Munich since 2008.

Sunil Manghani is Reader in Critical and Cultural Theory and Director of Doctoral Research at the Winchester School of Art, University of Southampton. He is an associate editor for Theory Culture \& Society and an editorial board member for the Journal of Contemporary Painting. He is the author of Image Studies: Theory and Practice (Routledge, 2013); Image Critique \& the Fall of the Berlin Wall (Intellect, 2008); editor of the four-volume anthology Images: Critical and Primary Sources (Bloomsbury, 2013); and co-editor of Images: A Reader (Sage, 2006), an anthology of writings on the image from Plato to the present; and Painting: Critical and Primary Sources (Bloomsbury, 2015). He is also co-editor of Farewell to Visual Studies? (Penn State University Press, 2015), which is the final volume in the Stone Summer Theory Institute series, produced by School of the Art Institute of Chicago. 